\title{
Determination and Characterization of Ciliary ATPase in the Presence of Serum from Cystic Fibrosis Patients
}

\author{
PHILIP M. FARRELL, (44) GARY N. FOX, AND SAMUEL S. SPICER \\ Pediatric Metabolism Branch, National Institute of Arthritis, Metabolism, and Digestive Diseases; Neonatal and \\ Pediatric Medicine Branch, National Institute of Child Health and Human Development, National Institutes of \\ Health, Bethesda, Maryland; and Department of Pathology, Medical College of South Carolina, Charleston, South
} Carolina, USA

\section{Extract}

The purpose of this investigation was twofold: $(l)$ to identify and characterize the enzymatic ATP hydrolysis system of epithelial cilia, and (2) to develop a quantitative, biochemical test for the ciliotoxic cystic fibrosis (CF) factor based on inhibition of ATP utilization by ciliary preparations. Our rationale for selecting this system for CF factor analysis relates to the tight and essential mechanochemical coupling of functioning cilia. Using rabbit tracheal epithelium as the source, a high molecular weight $(>200,000)$ ATPase was identified, partially purified, and extensively characterized. The properties of this protein were similar to those observed in previous studies of others with flagellar and ciliary dynein (the motility-associated ATPase) isolated from microorganisms. Analysis of the $\mathrm{pH}$ profile revealed a broad range of high enzymatic activity between 6.5 and 9. Studies with potential cation activators showed that the enzyme is activated equally by either $\mathrm{Ca}^{2+}$ or $\mathrm{Mg}^{2+}$ in equimolar concentrations. No activation occurred in the presence of $\mathrm{Zn}^{2+}, \mathrm{Na}^{+}, \mathrm{H}^{+}$, or $\mathrm{Na}^{+}$plus $\mathrm{K}^{+}$and the effect of $\mathrm{Mg}^{2+}$ or $\mathrm{Ca}^{2+}$ was not inhibited by $\mathrm{Na}^{+}, \mathrm{K}^{+}$, or $\mathrm{Na}^{+}$ plus $\mathrm{K}^{+}$. The enzyme hydrolyzed $\mathrm{Mg}^{2+}$-containing solutions of UTP, CTP, and ADP at 51-54\% the rate of ATP dephosphorylation, whereas Mg-deoxy-ATP was hydrolyzed $79 \%$ as effectively as ATP.

Using a newly devised, analytical technique with $\left[\gamma^{-32} \mathrm{P}\right] \mathrm{ATP}$ as the substrate, the ATP hydrolysis of various ciliary preparations from rabbit trachea and oyster gill (including motile suspensions) was monitored in the presence of sera from $\mathrm{CF}$ homo- and heterozygotes. Reproducible rates of ATP dephosphorylation averaging $27 \mathrm{nmol} / \mathrm{min} / \mathrm{mg}$ protein were demonstrable with homogenates of ciliated epithelium. None of the test systems evaluated, however, were capable of demonstrating CF-related differences in ATPase activity or ATP utilization. Although these attempts have been unsuccessful thus far, the approach described in this report provides an example of an objective, quantitative, biochemical assessment of ciliary function.

\section{Speculation}

The ciliotoxic cystic fibrosis factor does not disrupt ciliary motility by interfering with energy utilization. Other mechanisms of action which are possible include impairment of ATP production, disturbance of ionic constituents essential for normal motility, and alteration in mucous gland secretion products. A change in emphasis away from the current qualitative, subjective bioassay techniques is indicated in the interest of developing a clinically useful genetic screening test.

The incidence of CF is approximately 1 in 2,000 live births among Caucasians (14). It follows that about $5 \%$ of the Caucasian population or approximately 10 million Americans are carriers, emphasizing the importance of a method for heterozygote detec- tion. Techniques based on serum-induced alterations in ciliary beat have received a great deal of attention as possible CF genotype assay systems since first reported by Spock in 1967 (30). Demonstration of the ciliotoxic factor has been based on various bioassays which utilize either cultured rabbit tracheal epithelium $(12,13,30)$ or oyster gill $(4,5)$, the end point being disruption or cessation, respectively, of normal, rhythmic ciliary beat. Dysrhythmia or stasis, as originally reported, takes place only in the presence of the CF factor, as found in sera from cystic fibrosis homo- and heterozygotes. However, further experience with the bioassays $(3$, $9,28)$, a double-blind study (36), and slow motion analysis of high speed cinemicrographs of ciliary systems (10) suggest that these methods are difficult to reproduce and are not reliable enough for clinical use in genetic screening (27). The techniques, in fact, suffer from several disadvantages in that they are qualitative and subjective, utilize nonhomogeneous test material, are subject to seasonal artifacts, and are influenced by a number of additional variables, such as ionic environment, $\mathrm{pH}$, and temperature, which are difficult to control in the bioassays $(1,3,19,28)$.

In the past several years, advances from basic investigations with microorganisms have clarified flagellar and ciliary structure, metabolism, and enzymology (32). In particular, the work of Gibbons and associates $\left(\begin{array}{ll}2 & 22\end{array}\right)$ has been instrumental in providing basic insights into the molecular mechanisms for ciliary motility. An ATPase, somewhat analogous to myosin and referred to as dynein, has been demonstrated by that group as well as by others $(6-8,34)$; further, it has been shown that the enzymatic hydrolysis of ATP in various motile preparations is tightly coupled to, and reflective of, ciliary metabolism and beat frequency $(6-8,21)$.

The purpose of this investigation was twofold: $(l)$ to identify and characterize the presumed ATP hydrolysis system of epithelial cilia, and (2) to develop an objective, quantitative, reproducible, biochemical test for the ciliotoxic CF factor. Since CF sera reportedly cause either dysrhythmic ciliary beat or stasis, it seemed reasonable to propose that the rate of ATP hydrolysis by preparations of cilia might be affected by such samples. This report describes a study of energy-connected metabolism of cilia from rabbit tracheal epithelium and oyster gill. Data are presented on ATP hydrolysis by various ciliary preparations in the presence of serum samples from normal subjects and those of the CF genotype. Because of the relatively large amount of inorganic phosphorus present in serum, which leads to unacceptably high blank values in conventional, colorimetric ATPase procedures, it was necessary to devise a new, radioisotopic analytical technique for this purpose; the procedure is described fully herein.

\section{MATERIALS AND METHODS}

\section{SERUM SAMPLES}

Blood was obtained via venipuncture from cystic fibrosis patients who had been diagnosed unequivocally on the basis of a 
positive sweat test and the presence of both pancreatic insufficiency and characteristic pulmonary disease. Parents of these patients were utilized as obligate $C F$ heterozygotes and agematched, normal volunteers were also bled at the same time. Samples were collected and processed in plastic containers and sera were tested when fresh.

\section{RABBIT TRACHEAL. PROCEDURES}

Preparation and culture of the rabbit tracheal (RT) epithelium from weanling New Zealand White rabbits were performed following exactly the method of Conover et al. $(12,13)$. Briefly, the procedure, which was taught to us by Dr. Conover, entailed aseptic removal of the trachea, immediate, thorough washing with basal Eagle medium at $\mathrm{pH} 7.4$, and careful removal of the epithelium with a freshly sterilized scalpel. Subsequently, the mucosal sheets were rinsed with medium, transferred to a sterile watch glass, and divided into $15-20$ pieces of $2-3 \mathrm{~mm}^{2}$ size. The latter were placed in Falcon 30- $\mathrm{ml}$ culture flasks and incubated in $3 \mathrm{ml}$ of the above medium supplemented with $10 \%$ fetal calf serum, $1 \% 200 \mathrm{mM}$ L-glutamine, penicillin $(50 \mathrm{u} / \mathrm{ml})$, and streptomycin $(50 \mu \mathrm{g} / \mathrm{ml})$. Explanted epithelial sheets were incubated at $37^{\circ}$ for 110 days before use.

Preparation of RT explant homogenates for measuring ATPase activity was carried out as follows: 30 explants were screened for active ciliary beat, placed in $3.0 \mathrm{ml}$ of $4^{\circ}$ assay medium $(0.05 \mathrm{M}$ Tris- $\mathrm{HCl}, \mathrm{pH} 8.0,0.30 \mathrm{mM}$ EDTA), and homogenized with a glass-on-glass tissue grinder until an even mixture was obtained for immediate use. Minced RT preparations differed from the homogenates in that explants were minced vigorously with a small dissecting scissors in a minimum volume of assay medium before dilution to the same protein concentration employed in the homogenates. Minced samples were sufficiently fine to permit pipetting through $50-100-\mu 1$ micropipettes (37). Motile RT preparations were prepared identically to explants except that the tracheal membrane was divided into sheets of approximately $8-\mathrm{mm}^{2}$ size. Each epithelial sheet was weighed and placed in a plastic tube for assay.

\section{OYSTER GILL. PREPARATIONS}

Oysters of the Crassostrea virginica strain were obtained fresh from the Chesapeake Bay through courtesy of the Maryland Department of Natural Resources. Gills, removed by dissection using the technique of Bowman, et al. $(4,5)$, were washed with filtered sea water, and were demonstrated in all instances to possess motile cilia. Minced gill samples and homogenates were prepared analogously to RT preparations except that explant-sized squares of gill membrane were substituted for the RT explants. Routine examination of minced gills under light microscopy revealed that these samples were invariably motile.

\section{ANALYSIS AND CHARACTERIZATION OF CILIARY ATPase}

In order to measure ATP hydrolysis in the presence of phosphorus-containing serum, a new, radioisotopic procedure was devised using $\left[\gamma^{-{ }^{32}} \mathrm{P}\right]$ ATP and cold, carrier nucleotide. Disodium ATP-tetrahydrate and a divalent cation activator (usually $\mathrm{Mg}^{2+}$ or $\mathrm{Ca}^{2+}$ ) were added in a ratio of $1: 1.5$ to a $0.02 \mathrm{M}$ Tris- $\mathrm{HCl}$ buffer, initially adjusted to $\mathrm{pH} 8.0$, and then retitrated to $\mathrm{pH} 8.0$ after addition of the acidic metal-nucleotide. To the cold ATP solution at $4 \mathrm{mM}$ concentration, adenosine $-5^{\prime}-\left[\gamma_{-}{ }^{32} \mathrm{P}\right]$ triphosphate tetrasodium salt $(38)(1.5-3 \mathrm{mCi} / \mathrm{ml}, 50-100 \mathrm{Ci} / \mathrm{mmol})$ was added to provide a specific activity of $2-10 \mu \mathrm{Ci} / \mathrm{ml}$. Volume changes due to addition of the isotope were no more than $0.5 \%$ and changes in ATP concentration were insignificant. All ATP solutions were kept on ice during assay procedures and were stored at $-40^{\circ}$ between usages.

Homogenates and other preparations of cilia were pipetted into 5-ml glass conical Pyrex centrifuge tubes. Preincubations were performed at the same temperature as the incubation, either at $25^{\circ}$ or at $37^{\circ}$. Preincubation and incubation times varied from 0.30 $\mathrm{min}$, and from $10-20 \mathrm{~min}$, respectively, depending on the experiment. Short preincubations were employed to allow tubes to equilibrate at assay temperature, and longer preincubations were used when potential enzyme modifiers such as CF sera were being tested. Enzymatic reactions were initiated by addition of $50 \mu 14$ $\mathrm{mM}$ ATP solution to bring the total assay volume to $200 \mu \mathrm{l}$, and

\section{FRONT}
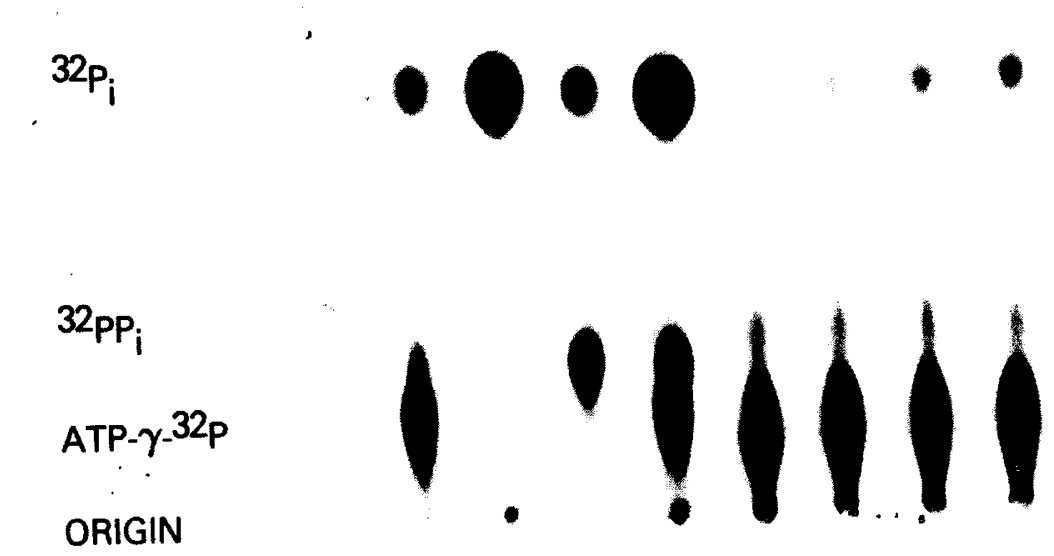

Fig. 1. Analysis of ciliary ATPase activity: autoradiography of a cellulose thin layer sheet containing ${ }^{32}$ P-labeled standards and aliquots of a typical incubation mixture (last four samples on the right). 
were terminated by addition of $50 \mu$ l cold $50 \%$ trichloroacetic acid and placement of the tube on ice. The incubation tubes were centrifuged briefly in early studies to remove protein before quantitation; however, this step was found to be unnecessary and was later eliminated.

Quantitation was achieved by measurement of ${ }^{32} \mathrm{P}_{1}$ liberated and $\left[\gamma^{-32} \mathrm{P}\right]$ ATP remaining in the incubation mixture. For this purpose, a $2-\mu \mathrm{l}$ aliquot $\left(10^{-3}-10^{-2} \mu \mathrm{Ci}\right)$ was spotted on a $160-\mu \mathrm{m}$ cellulose thin layer sheet. Chromatography was then performed in a solvent system developed for optimal separation of ATP and $P_{1}$, consisting of $100 \mathrm{ml} n$-propyl acetate, $50 \mathrm{ml} 88 \%$ formic acid, and $30 \mathrm{ml} \mathrm{H}_{2} \mathrm{O}$. $R_{F}$ values consistently reproduced in this system were 0.08 for ATP, 0.18 for pyrophosphate, and 0.51 for $P_{1}$, as shown in Figure 1 . The $\left[\gamma^{-32} \mathrm{P}\right] A T P$ and ${ }^{32} P_{1}$ were localized by autoradiography on Kodak NS2T medical x-ray film (39) for a minimum of $16 \mathrm{hr}$, and the radioactive portions transferred to glass scintillation vials containing $10 \mathrm{ml}$ Aquasol (40). Samples were counted with a Beckman model LS-255 scintillation counter. Percentage of hydrolysis of ATP was calculated from the ratio of counts per min of $P_{1}$ to the total counts per min of ATP $+P_{1}$ spots. Results were converted to micromoles of $P_{1}$ per min per $\mathrm{mg}$ of protein using the ATP concentration present in this assay and the protein concentration as determined by the method of Lowry et al. (25).

Modifications of the above procedures were necessary in some experiments, as follows. (I) For pH profile studies, Tris-acid maleate buffers, $0.05 \mathrm{M}$, were prepared with $\mathrm{pH}$ ranging from 5.5-9.0. Cilia were homogenized at 3 times the usual concentration in isotonic $(0.32 \mathrm{M})$ sucrose, then diluted with 2 parts of buffer to obtain enzyme homogenate of desired $\mathrm{pH}$. MgATP solutions were prepared at each $\mathrm{pH}$ in Tris-acid maleate buffers. (2) Enzyme specificity studies with various nucleotides were performed at saturating substrate concentrations, utilizing incubations of $1 \mathrm{ml}$ homogenate and $1 \mathrm{ml}$ nucleoside phosphate solutions. Aliquots were assayed for $P_{1}$ by the method of Fiske and SubbaRow (18). (3) Activation by purified actin (41) was assessed using essentially the techniques of Eisenberg and Moos (16).

In order to isolate the ATPase protein, rinsed epithelial sheets, freshly prepared from four rabbit tracheae, were minced and homogenized in $0.05 \mathrm{M}$ Tris- $\mathrm{HCl}, \mathrm{pH} 8.0$, containing $0.30 \mathrm{mM}$ EDTA. After centrifugation at $40,000 \times g$ for $15 \mathrm{~min}$ and concentration under nitrogen with an Amicon filtration apparatus, the sample was subjected to molecular exclusion chromatography on a column, $2.4 \times 26 \mathrm{~cm}$, of Sephadex G-200. After analysis of ATPase activity and protein concentration, selected fractions were electrophoresed on sodium dodecyl sulfate (SDS)-polyacrylamide gels according to the procedures of Fairbanks et al. (17); gels were calibrated for molecular weight at the same time using purchased protein standards.

\section{PREPARATION OF SAMPLES FOR ELECTRON MICROSCOPY}

Samples of rabbit tracheal epithelium or oyster gill were placed in $5 \mathrm{ml}$ conical Pyrex centrifuge tubes to which were added $100 \mu 1$ 4\% fibrinogen and, after mixing, 1 drop thrombin solution. Portions of the oyster gill were exposed to fresh sertm from normal subjects or cystic fibrosis patients for $45 \mathrm{~min}$ at room temperature and then added to other centrifuge tubes and clotted similarly. To the thrombin-induced clot, $2 \mathrm{ml} 3 \%$ glut araldehyde in $0.1 \mathrm{M}$ sodium cacodylate buffer, $\mathrm{pH} 7.4$, were added. After $5 \mathrm{~min}$, the clots were minced in the fixative and retained therein for 0.52 $\mathrm{hr}$ before centrifuging and washing free of glutaraldehyde with three rinses in $3 \mathrm{ml} 7.5 \%$ sucrose-cacodylate buffer. Part of each specimen fixed $30 \mathrm{~min}$ was sectioned in the cryostat and then stained with dialyzed iron (35) to demonstrate acid mucosubstance or with the Wachstein-Meisel method (33) to localize ATPase ultrastructurally. The minced clots and cryostat sections were then dehydrated through graded alcohols and propylene oxide and embedded in Epon. Thin sections that had been stained sequentially with uranyl acetate and lead citrate, as well as unstained thin sections, were examined with an AEI-6B electron microscope.
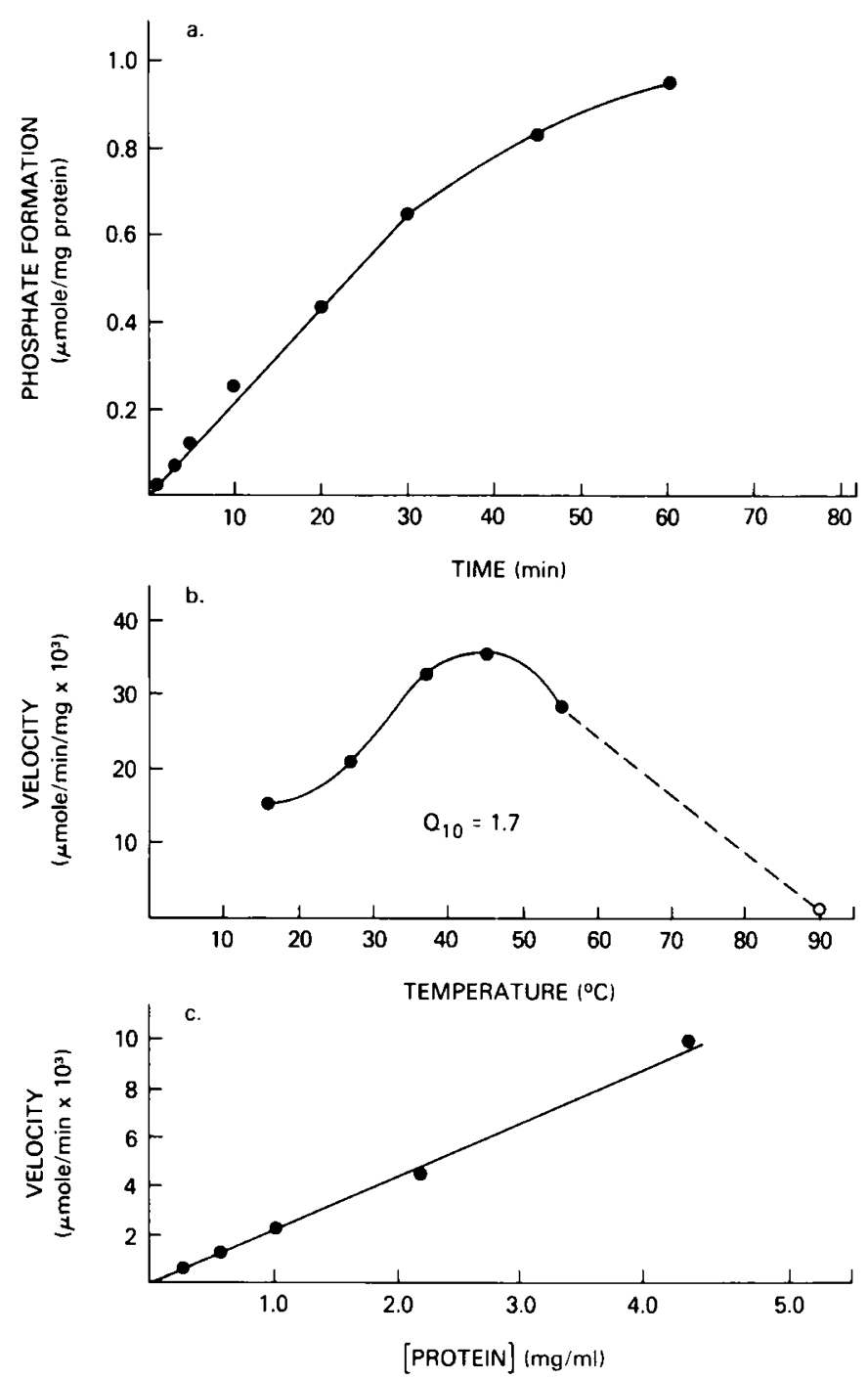

Fig. 2. Effect of incubation time, temperature, and protein concentration on $\mathrm{MgATP}$ hydrolysis by homogenates of rabbit tracheal epithelium.

\section{RESULTS}

Characterization of the ciliary ATP hydrolysis system as catalyzed by homogenates of rabbit tracheal epithelium is shown in Figures 2-4. Under these assay conditions, linear generation of the $P_{1}$ product or initial velocity was therefore maintained for $30 \mathrm{~min}$. As illustrated in Figure 2, velocity was proportional to protein concentration in the $0.25-4 \mathrm{mg} / \mathrm{ml}$ range employed in this system. Analysis of temperature variations revealed that the enzyme reaches maximal velocity at about $45^{\circ}$, and shows a rapid decline in activity above $45^{\circ}$. The calculated $Q_{10}$, as measured between $27^{\circ}$ and $37^{\circ}$, is 1.7 . The $\mathrm{pH}$ curve revealed a broad range of high enzymatic activity between 6.5 and 9 . Studies with potential cation activators revealed that the enzyme was activated equally by either $\mathrm{Ca}^{2+}$ or $\mathrm{Mg}^{2+}$ in equimolar concentrations. No activation occurred in the presence of $\mathrm{Zn}^{2+}, \mathrm{Na}^{+}, \mathrm{K}^{+}$, or $\mathrm{Na}^{+}$plus $\mathrm{K}^{+}$and the effect of $\mathrm{Mg}^{2+}$ or $\mathrm{Ca}^{2+}$ was not inhibited by $\mathrm{Na}^{+}, \mathrm{K}^{+}$, or $\mathrm{Na}^{+}$plus $\mathrm{K}^{+}$. The activation of the enzyme by $\mathrm{Mg}^{2+}$ followed a hyperbolic curve, as shown in Figure 4, with maximal velocity attained when the divalent cation concentration equalled the ATP concentration in the assay $(1.0 \mathrm{mM})$. Kinetic studies with MgATP. as summarized in Figure 4, yielded an apparent $\mathrm{K}_{\mathrm{m}}$ value of $5.7 \times 10^{-4} \mathrm{M}$.

The enzyme hydrolyzed $\mathrm{Mg}^{2+}$-containing solutions of UTP. CTP. and ADP at $51.54 \%$ the rate of ATP dephosphorylation. whereas Mg-deoxy-ATP was hydrolyzed $79 \%$ as effectively as ATP. No activity was present with respect to hydrolysis of 


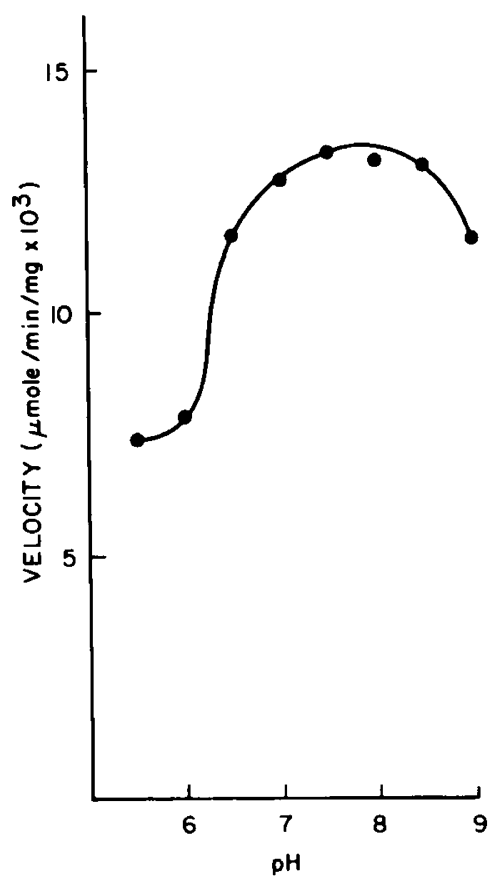

Fig. 3. Effect of $\mathrm{pH}$ on ciliary ATPase activity as measured with homogenates of rabbit tracheal epithelium. Initial enzyme velocities were measured as described in the text.

p-nitrophenyl phosphate, a measure of nonspecific alkaline phosphatases. Addition of actin to the assay system produced no activation. Potential enzyme inhibitors studied include ouabain, sodium fluoride, $p$-chloromercuribenzoate, sodium iodoacetamide, and spermidine; none of these influenced enzyme activity in concentrations of $10^{-3} \mathrm{M}$. EDTA in a concentration of $10^{-2} \mathrm{M}$ completely abolished enzymatic activity.

Purification to a $1 \theta$-fold degree was achieved using high speed centrifugation, Amicon filtration, and molecular exclusion chromatography. The major portion $(95 \%)$ of the enzymatic activity was eluted in the void volume of the Sephadex G-200 column as shown in Figure 5. This pattern of elution is consistent with a molecular weight of $>200,000$, as was supported by SDS-gel chromatography of fractions $18-24$.

In the minced oyster gill preparations, a linear relationship was observed between ATP hydrolysis and viscosity (Fig. 6). This is consistent with the microscopically observable motility of such preparations on light microscopy and with literature values on beat frequency, as related to viscosity changes brought about by increasing concentrations of methylcellulose (1).

Electron microscopic examination of the minced rabbit trachea and oyster gill samples processed for morphologic examination or cytochemistry revealed epithelial cells with fine structure of normal appearance. The cilia and plasma membrane of the gill epithelial cells appeared to be intact, the nuclei disclosed normal contour and heterochromatin distribution, and the cytoplasm enclosed numerous well preserved mitochondria and profiles of endoplasmic reticulum (Figs. 7 and 8). A coat of acid mucosubstance was visualized on the surface of the cilia with the dialyzed iron method (Fig. 7). ATPase activity was not evident, possibly because of inactivation of enzyme by fixative, but both controls and specimens incubated for ATPase showed nonenzymatic lead deposits in cisternae of granular reticulum (Fig. 8). No difference was evident in the fine structure of specimens incubated in normal serum compared with cystic fibrosis serum, and those exposed to cystic fibrosis serum disclosed dialyzed iron staining indicative of acid mucosubstance on their surface.

Results obtained in the presence of CF sera are presented in Table 1. As is evident from the data, no differences were detected in the presence of $50 \% \mathrm{CF}$ sera as compared with control sera. Both RT and oyster gill homogenates hydrolyzed ATP at a rate of $25-30 \mathrm{nmol} / \mathrm{min} / \mathrm{mg}$ protein, with activation by $\mathrm{Ca}^{2+}$ being approximately equal to $\mathrm{Mg}^{2+}$ in both assay systems. Minced ciliary preparations from oyster gill demonstrated ATP hydrolysis rates considerably lower than that of the homogenates, as has been observed in mechanochemical-coupled flagella (8). The fact that no significant differences were observed between CF and control sera in the motile ciliary preparations strongly suggests that the cilia were beating normally, since altering the viscosity significantly modifies the amount of ATP utilized.

\section{DISCUSSION}

In addition to basic studies designed to identify and characterize the presumed ATP hydrolysis system of epithelial cilia, a major objective of this research was to develop a cilia-based, biochemical assay for detection of the cystic fibrosis genotype. Such a technique would offer several advantages over the current bioassays if it fulfilled our proposed minimal criteria of being objective, quantitative, and highly reproducible, and utilizing homogeneous or quantifiable test material. It was postulated that the disruption of ciliary beat observed in bioassays may operate on a biochemical level either by altering the motility-associated ATPase enzyme in cilia or by disturbing ATP utilization per se.

The rationale for selection of the ATP hydrolysis system is as follows. ( $I$ ) It is reasonable to assume that pronounced disturbances in the general function of a tissue such as cilia, which utilizes large amounts of energy, could operate on a biochemical level by altering formation or use of the ultimate energy source, ATP. (2) The studies of Gibbons et al. (20 22) and of Brokaw and Benedict
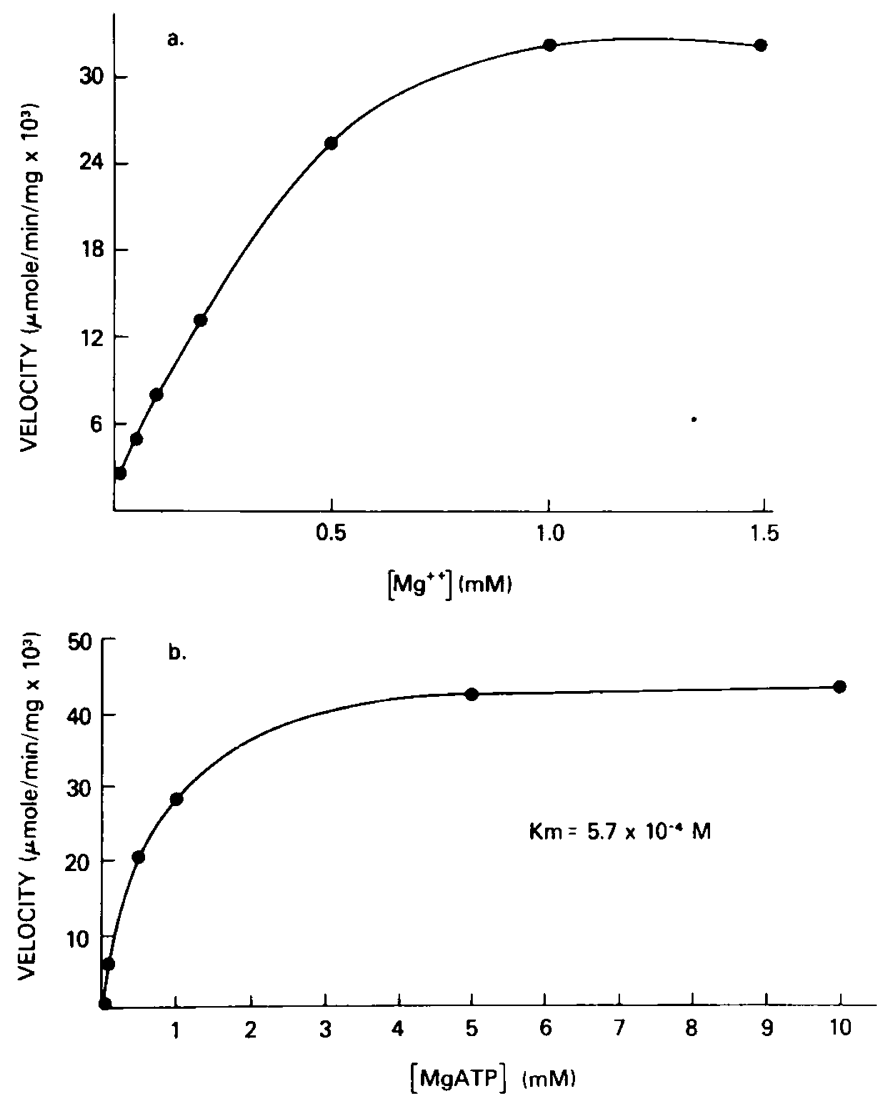

Fig. 4. Effect of $\mathrm{Mg}^{2+}$ concentration and $\mathrm{MgATP}$ concentration on ciliary ATPase activity. Initial enzyme velocities were measured as described in the text. A final ATP concentration of $1 \mathrm{mM}$ was employed in the $\mathrm{Mg}^{2+}$ activation studies. 


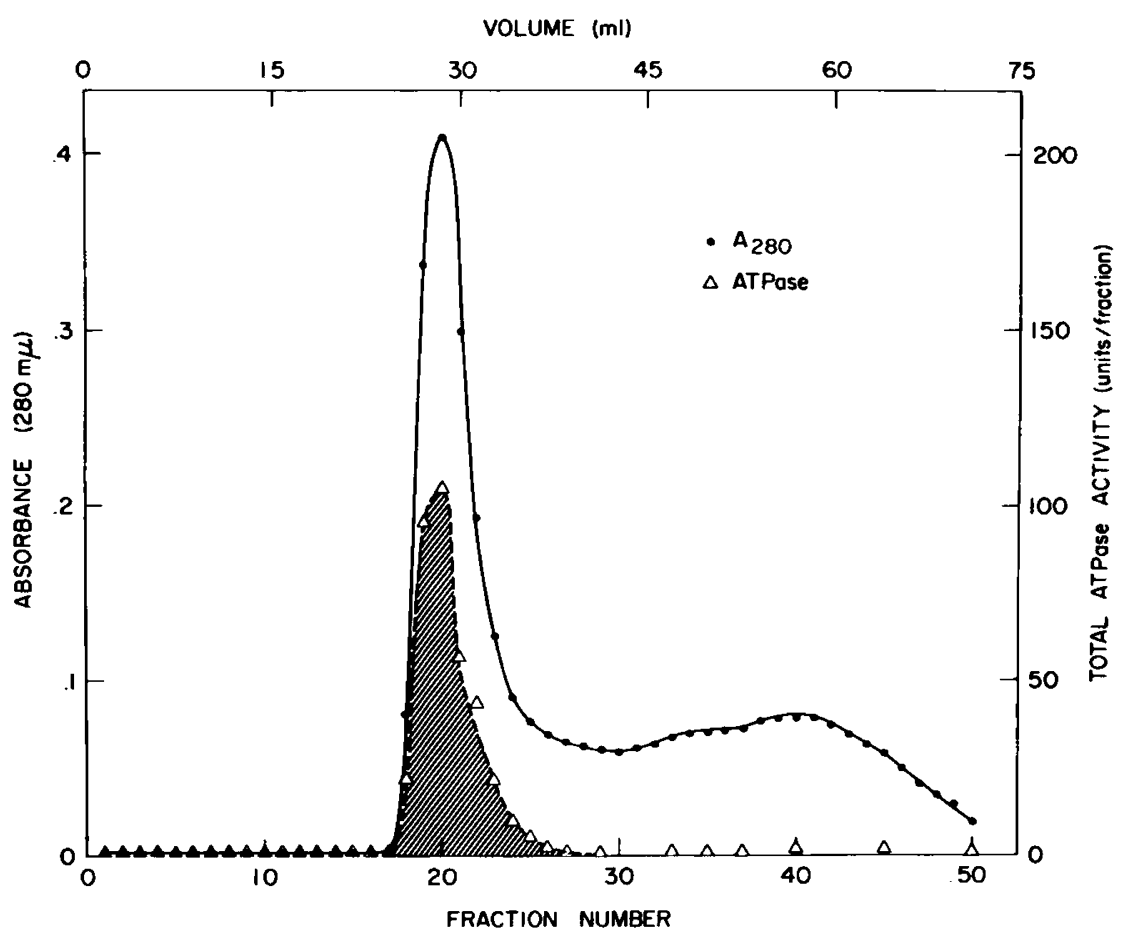

Fig. 5. Sephadex G-200 column chromatography of a partially purified protein preparation from rabbit tracheal epithelium. Fractions were eluted

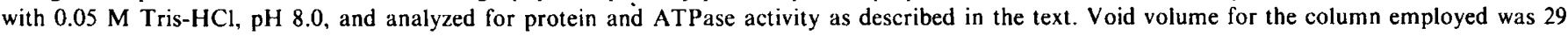
$\mathrm{ml}$ as determined with blue dextran, a solution of which eluted coincidently with the peak of ATPase activity.

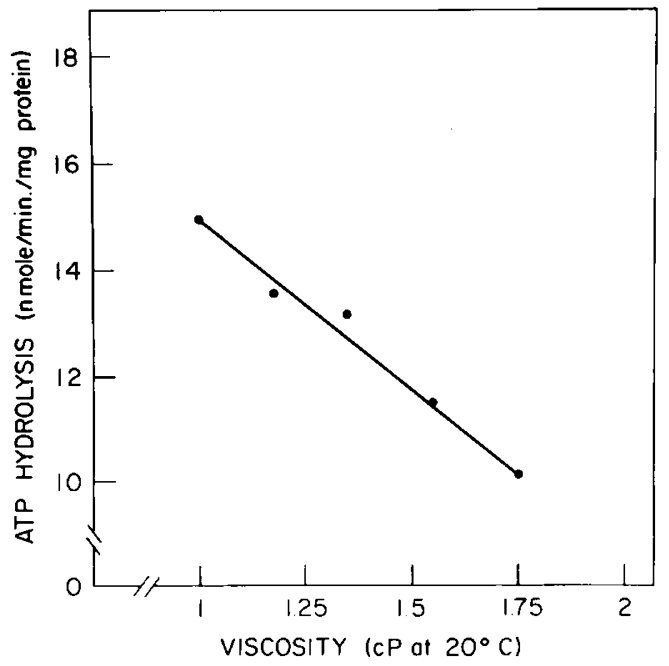

Fig. 6. Effect of increasing viscosity on ATP utilization by minced oyster gill preparations. Incubations with motile cilia preparations were performed at $20^{\circ}$ in sea water containing $0,0.05,0.10,0.15,0.20$, and $0.25 \%$ methylcellulose to increase viscosity and reduce beat frequency in a linear fashion $(1,7)$. Viscosity values for methylcellulose solutions expressed in centipoise units $(\mathrm{cP})$ were taken from the literature (7).

(6-8) have demonstrated clearly that in beating flagella and cilia, motility and ATP hydrolysis are tightly coupled by the enzyme dynein, a high molecular weight ATPase. Therefore, it would be strongly suspected that alterations in motility, particularly ciliostasis, would alter ATP utilization. (3) Although not established unequivocally, current evidence from several groups indicates that $\mathrm{Ca}^{2+}$-activated ATPases are abnormal in cell preparations from $\mathrm{CF}$ homozygotes and in other systems exposed to fluids from such patients $(11,23)$.

Therefore, in search of an ideal, quantitative biochemical assay, we sought to investigate ATP hydrolysis by cilia in the presence of CF and normal sera. To accomplish this, because of the high inorganic phosphorus content of serum which made small changes in $P_{1}$ undetectable colorimetrically, it was necessary to devise a new, routine analytical technique using $\left[\gamma^{32} \mathrm{P}\right] \mathrm{ATP}$. The procedure developed in this study permitted us to measure ATP dephosphorylation reproducibly in as many as $100-200$ samples/day and provided sufficient sensitivity. Two basic approaches were utilized to assess CF sera: in the first, nonmotile preparations of the cilia were used to assay ciliary ATPase; in the second, motile ciliary suspensions, prepared by mincing oyster gill, were evaluated to determine the rate of ATP utilization for beating.

In the nonmotile assay system, a protein which hydrolyzed ATP was isolated from homogenates of rabbit tracheal epithelium. To characterize this ciliary ATPase, isolated for the first time in this investigation, considerable basic information was gathered experimentally, as shown in Figures 2-5 and as summaried in Table 2. Several lines of evidence strongly suggest that this protein represents the motility coupled (dynein) ATPase, as opposed to a nonmuscle myosin, a membrane-associated enzyme (e.g., Na/K ATPase), or a nonspecific alkaline phosphatase (see Table 2). Properties of dyncins include high molecular weight, activation by $\mathrm{Mg}^{2+}$ and $\mathrm{Ca}^{2+}$ but not $\mathrm{Na}^{+}$or $\mathrm{K}^{+}$, compliance with classic Michaelis-Menten kinetics with $K_{m}$ values in the range of $10^{-5}-10^{-3} \mathrm{M}$, broad $\mathrm{pH}$ optima between 7 and 9 , relative nucleotide nonspecificity, insensitivity to ouabain, resistance to sulfhydryl inhibitors, low nonspecific alkaline phosphatase activity, lack of activation by muscle actin, and localization in the arms of the outer doublets of the cilia $(6-8,20-22,32,34)$. In addition, the abundance of the enzyme in the RT epithelium preparations supports the view that the enzyme is the motility-related ATPase, since in other axonemal systems, dynein has been shown to constitute the majority of the soluble protein and up to $84 \%$ of the ATPase activity $(8,32)$. In contrast to dyneins, membraneassociated $\mathrm{Na} / \mathrm{K}$ "pump" ATPases are activated by monovalent cations, inhibited by cardiac glycosides, notably ouabain, and are highly specific with respect to nucleotide substrates (29). 

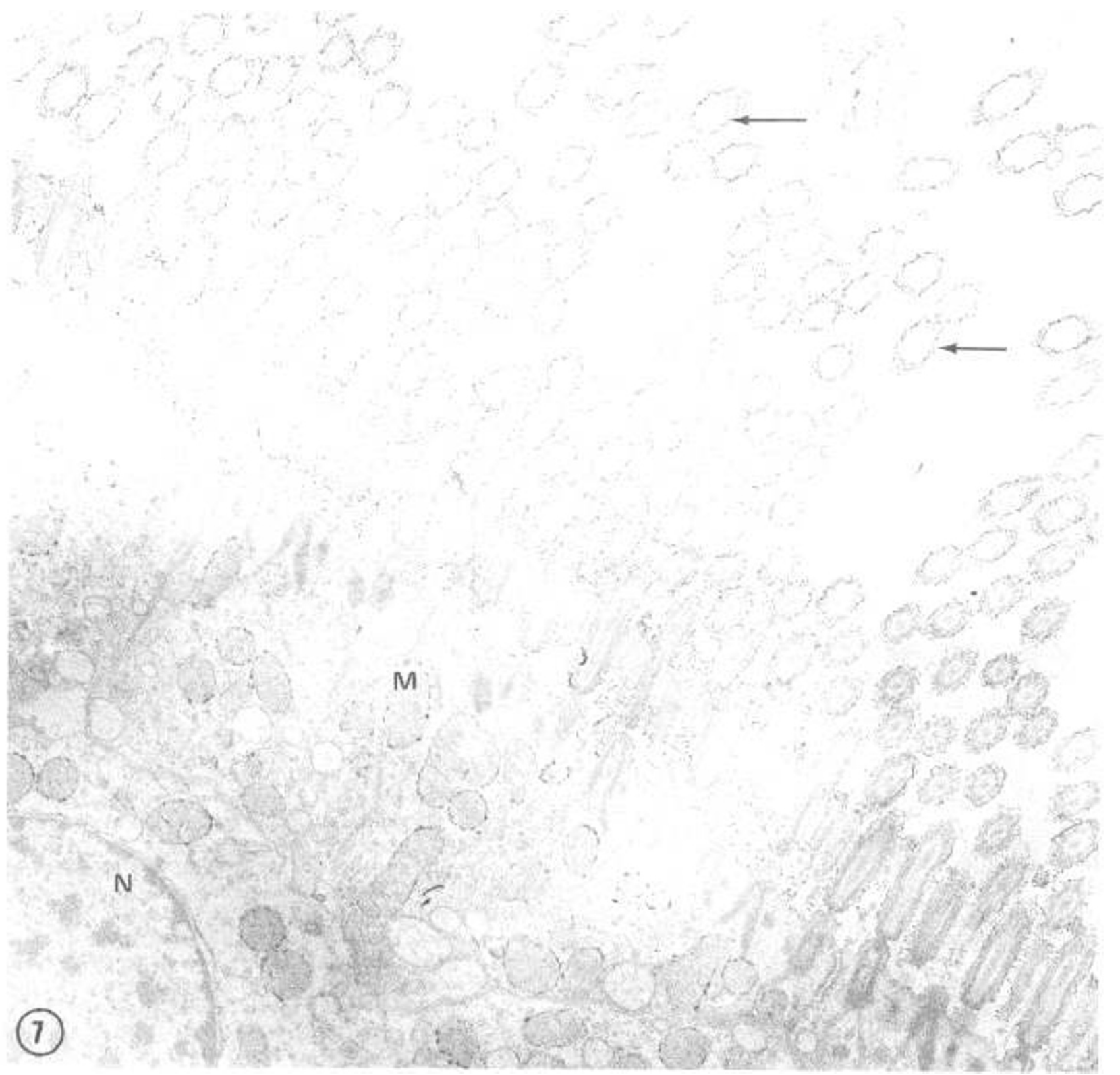

Fig. 7. Minced oyster gill tissue stained with dialyzed iron. This micrograph reveals fine electron opaque deposits indicative of acid mucosubstance coating the surface of the cilia (arrows). The cilia, cytoplasmic membranes, basal bodies, mitochondria $(M)$, and nucleus $(N)$ appear normal in structure, $\times \quad 15,000$

The foregoing basic studies permitted us to develop a potential assay for the hypothetical CF factor with analyses being carried out at $\mathrm{pH} 8.0$ in the presence of $25-50 \%$ fresh serum. Ciliary preparations were preincubated in the presence of sera at room temperature or at $37^{\circ}$ for $30 \mathrm{~min}$. Numerous ATP hydrolysis test systems were developed, characterized, and then evaluated in the presence of $\mathrm{CF}$ and control sera. The systems employed the following materials: $(I)$ homogenized explants of rabbit tracheal epithelium; (2) homogenized oyster gill; (3) intact rabbit tracheal epithelium (results not shown); (4) minced rabbit tracheal epithelium (results not shown); and (5) minced oyster gill. None of these systems demonstrated differences in ciliary ATP hydrolysis in the presence of CF sera. In particular, it was surprising that the minced oyster gill assay system failed to respond to CF sera since the oyster cilia in this preparation retained motility as assessed by three characteristics: $(l)$ observable ciliary beat under the light microscope, (2) predominance of intact cilia on electron microscopy, and (3) a linear relationship between ATP hydrolysis and viscosity, suggesting intact coupling between ATP utilization and motility (raising the viscosity to slow ciliary beat decreased ATP hydrolysis proportionately as depicted in Fig. 6). Since ATP dephosphorylation by minced oyster gill suspensions in the presence of CF sera is unaitered, it is quite probable that the cilia were beating normally despite the presumed presence of the CF factor. Thus, it is apparent that monitoring ATP utilization by beating cilia fails to demonstrate the CF ciliotoxic factor.

From the observation that CF serum neither influences ciliary ATPase activity nor diminishes ATP utilization by beating cilia, it is reasonable to conclude that the $\mathrm{CF}$ factor does not act on the level of energy utilization. Other possible mechanisms of action which might warrant investigation include: $(l)$ interference with ATP production by the abundant mitochondria in the supporting, basal cytoplasm of ciliated surfaces (see Fig. 7) (support for this mechanism comes from the studies of Bargman and Weisz (2) on mitochondrial preparations); (2) alteration in the important ionic constituents of ciliated cells and surfaces leading to a less favorable 


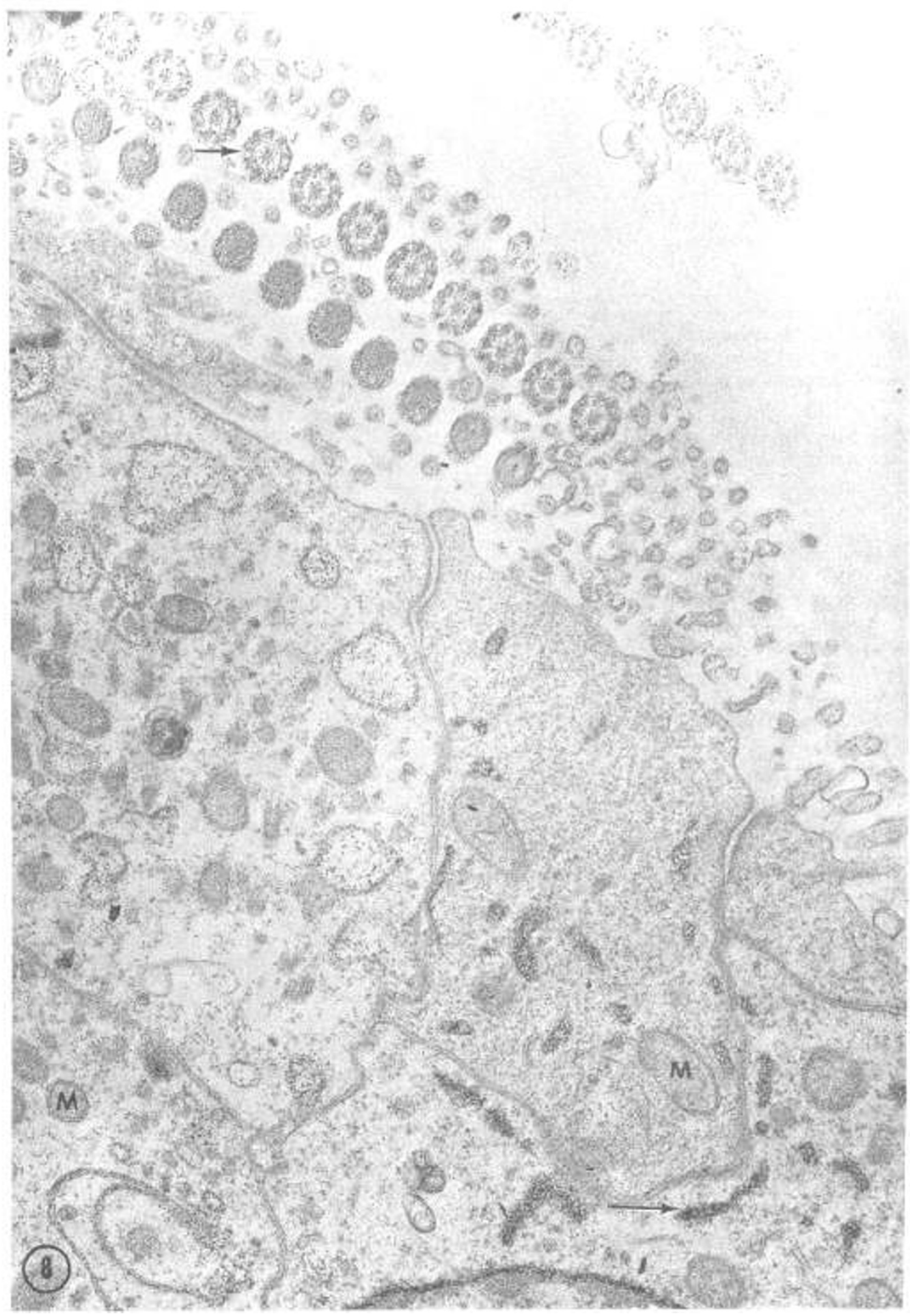

Fig. 8. Minced oyster gill tissue incubated in Wachstein-Meisel substrate for localizing ATPase. This sample shows well preserved mitochondria ( $M$ ) and other cellular structures. Although reaction product demonstrative of ATPase is not evident in this micrograph, presumably because of fixative inactivation, fine electron opaque deposits are present in cilia (short arrow), in collapsed (long arrow) or dilated profiles of endoplasmic reticulum, and in nuclear envelope at the bottom. Such deposits which were observed equally in controls incubated in substrate lacking ATP reflect sites with lead affinity, $\times \quad 25,000$. 
Table 1. Effect of serum ${ }^{1}$ on ciliary ATP hydrolysis ${ }^{2}$

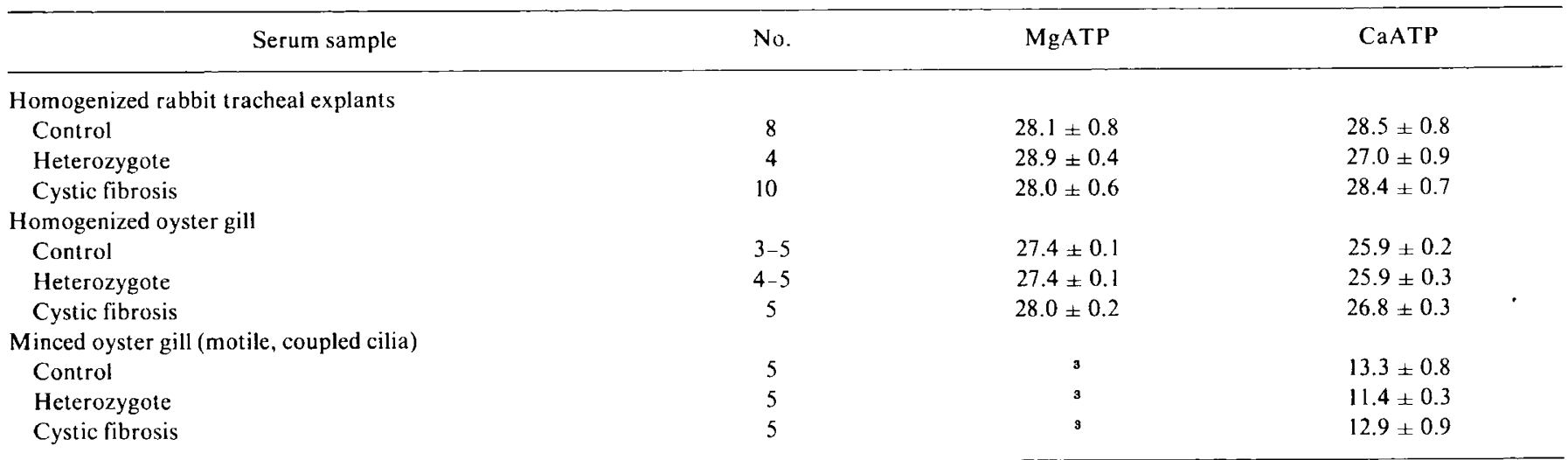

${ }^{1}$ Each assay was performed in the presence of $50 \%$ fresh serum.

${ }^{2}$ ATP dephosphorylation data are expressed as nanomoles of $\mathbf{P}_{i}$ liberated per min per $\mathrm{mg}$ of protein (mean \pm SEM).

${ }^{3}$ MgATP hydrolysis was not measured in the presence of serum with minced oyster gill preparations.

Table 2. ATPase from rabbit tracheal explants: The motility-associated ciliary (dynein) ATPase

\section{Evidence}

1. Abundance

2. High molecular weight of purified ATPase

3. Activation by $\mathrm{Mg}^{2+}$ or $\mathrm{Ca}^{2+}$ but not $\mathrm{Na}^{+}$or $\mathrm{K}^{+}$

4. Apparent $\mathrm{K}_{\mathrm{m}}$ for $\mathrm{MgATP}\left(5.7 \times 10^{-4} \mathrm{M}\right)$

5. $\mathrm{pH}$ profile

6. Relative nucleotide nonspecificity

7. Ouabain insensitivity

8. Resistance to sulfhydryl inhibitors

9. Low nonspecific alkaline phosphatase activity

10. Lack of activation by actin

milieu for beating $(15,24)$ (such an effect would concur with the findings of Mangos et al. (26) and others (31) on the "sodium transport inhibitory factor" present in some fluids of CF patients); (3) disturbance of the polyanionic, mucous surface coat demonstrated in Figure 8, or stimulation of excessive mucus expulsion by adjacent goblet cells, as has been observed upon addition of sera to ciliated epithelium $(5,28)$ (this mechanism would perhaps be in keeping with observations on the mucous secretions of $\mathrm{CF}$ patients (14)).

In conclusion, we are in agreement with the position (27) that at the present time there is no clinically reliable method based on ciliary assays for identifying CF heterozygotes. Although our attempts to develop a biochemical assay for the CF factor have thus far been unsuccessful, this study provides an example of an objective, quantitative, analytical technique. We suggest that a change in emphasis away from the current qualitative, subjective bioassay techniques is indicated in the interest of developing a clinically useful genetic screening test.

\section{SUMMARY}

An analytical technique based on ATP hydrolysis by preparations of cilia was developed in the hope that it would provide a reliable assay for the cystic fibrosis genotype. In the course of the study, a new procedure was devised for measuring enzymatic dephosphorylation of ATP. In addition, a method for preparing pipettable suspensions of motile cilia was developed and ciliary ATPase or dynein was isolated, partially purified, and extensively characterized Multiple ciliary preparations from rabbit tracheal epithelium and oyster gill were evaluated with respect to ATP hydrolysis in the presence of normal, CF, and CF heterozygote sera with no differences being detected.

\section{REFERENCES AND NOTES}

1. Aiello, E. L.: Factors affecting ciliary activity on the gill of the mussel Mytilus edulis. Physiol. Zool., 23: 120 (1960).

2. Bargman, G. J., and Weisz, L.: Cystic fibrosis (CF) and respiratory energy production. Pediat. Res., 8: 464 (1974).

3. Besley, G. J., Patrick, A. D., and Norman, A. P.: Inhibition of the motility of gil cilia of Dreissensia by plasma of cystic fibrosis patients and their parents. $J$. Med. Genet., 6: 278 (1969).

4. Bowman, H. B., Barnett, R. D., Matalon, R., Danes, S. B., and Bearn, G. A.: Cystic fibrosis: Fractionation of fibroblast media demonstrating ciliary inhibition. Proc. Nat. Acad. Sci. U. S. A., 70: 548 (1973).

5. Bowman, B. H., Lockhart, L. H., and McCombs, M. L.: Oyster ciliary inhibition by cystic fibrosis factor. Science, 164: 325 (1969).

6. Brokaw, C. J.: Adenosine triphosphate usage by flagella. Science, 156:76 (1967).

7. Brokaw, C. J., and Benedict, B.: Mechanochemical coupling in flagella. I Movement-dependent dephosphorylation of ATP by glycerinated spermatozoa. Arch. Biochem. Biophys. 125: 770 (1968).

8. Brokaw, C. J., and Benedict, B.: Mechanochemical coupling in flagella. III Effects of some uncoupling agents on properties of the flagellar ATPase. Arch Biochem. Biophys., 142: 91 (1971).

9. Cherry, J. D., Rodan, V. J., Regent, A. J., and Dorner, R. W.: The inhibition of ciliary activity in tracheal organ cultures by sera from children with cystic fibrosis and control subjects. J. Pediat., 79: 937 (1971)

10. Cheung, A. T., Jahn, T. L., and Lonseca, J. R.: In vitro study of the physiological effects of cystic fibrosis serum on rabbit tracheal explants. Cystic Fibrosis Club Abstr., 14: 28 (1973).

11. Cole, C. H., and Dirks, J. H.: Changes in erythrocyte membrane ATPase in patients with cystic fibrosis of the pancreas. Pediat. Res., 6: 616 (1972).

12. Conover, J. H., Bonforte, R. J., Hathaway, P., Paciuc, L., Conod, E. J., Hirschhorn, K., and Kopel, F. B.: Studies on ciliary dyskinesia factor in cystic fibrosis. I. Bioassay and heterozygote detection in serum. Pediat. Res., 7: 220 (1973).

13. Conover, J. H., Beratis, N. G., Conod, E. J., Ainbender, E., and Hirschhorn, K.: Studies on ciliary dyskinesia factor in cystic fibrosis: 11. Short term leukocyte cultures and long term lymphoid lines. Pediat. Res., 7: 224 (1973).

14. di Sant' Agnese, P. A., and Talamo, R. C.: Pathogenesis and physiopathology of cystic fibrosis of the pancreas. N. Engl. J. Med., 277: 1287 (1967).

15. Eckert, R.: Bioelectric control of ciliary activity. Science, 176: 473 (1972).

16. Eisenberg, E., and Moos, C.: Actin activation of heavy meromyosin adenosine triphosphate: Dependence on adenosine triphosphate and actin concentrations. J. Biol. Chem., 245: 2451 (1970).

17. Fairbanks, G., Steck, T. L., and Wallace, D. F. H.: Electrophoretic analysis of the major polypeptides of the human erythrocyte membrane. Biochemistry, 10 . 2606 (1971).

18. Fiske, C. H., and SubbaRow Y.: The colorimetric determination of phosphorus J. Biol. Chem., 66: 375 (1925).

19. Gray, J.: The mechanism of ciliary movement. IV. The relation of ciliary activity to oxygen consumption. Proc. Roy. Soc. London, 96: 95 (1924).

20. Gibbons, I. R.: Studies on the adenosine triphosphatase activity of $14 \mathrm{~S}$ and $30 \mathrm{~S}$ dynein from cilia of tetrahymena. J. Biol. Chem., 241: 5500 (1966).

21. Gibbons, 1. R. and Fronk, E.: Some properties of bound and soluble dynein from sea urchin sperm flagella. J. Cell. Biol., 54: 365 (1972).

22. Gibbons, B. H., and Gibbons, I. R.: Flagellar movement and adenosine triphosphate activity in sea urchin sperm extracted with Triton X-100. J. Cell Biol., 54: 75 (1972).

23. Horton, C. R., Cole, W. Q., and Bader, H.: Decreased $\left(\mathrm{Ca}^{++}\right)$-transport ATPase in cystic fibrosis erythrocytes. Biochem. Biophys. Res. Commun., 40: 505 (1970).

24. Kinosita, H., and Murakami, A.: Control of ciliary motion. Physiol. Rev., 47: 53 (1967). 
25. Lowry, O. H., Rosebrough, N. J., Farr, A. L., and Randall, R. J.: Protein measurement with the Folin phenol reagent. J. Biol. Chem., 193: 265 (1951)

26. Mangos, J. A., McSherry, N. R., and Benke, P. J.: A sodium transport inhibitory factor in the saliva of patients with cystic fibrosis of the pancreas. Pediat. Res., 1: 436 (1967).

27. Mangos, J. A., and Talamo, R. C.: Ciliary inhibitor factor of cystic fibrosis, p. 2 (National Cystic Fibrosis Research Foundation, Gap Conference Report, Atlanta, 1973)

28. Posselt, H. G., and Bender, S.: Heterozygote testing in cystic fibrosis: Experimental studies with cilia of the mussel Dreissena polymorpha. Z. Kinderheilk., 110: 98 (1971).

29. Skou, J. C.: Enzymatic basis for active transport of $\mathrm{Na}^{+}$and $\mathrm{K}^{+}$across cell membrane. Physiol. Rev., 45: 596 (1965).

30. Spock, A., Heick, H. M. C., Cress, H., and Logan, W. S.: Abnormal serum factor in patients with cystic fibrosis of the pancreas. Pediat. Res., $l: 173$ (1967).

31. Taylor, H., Mayo, J. W., Boat, T. F., and Matthews, L. W.: Standardized assay for the sodium reabsorption inhibitory effect and studies of its salivary gland distribution in patients with cystic fibrosis. Pediat. Res., 8: 861 (1974).

32. Warner, F. D.: Macromolecular organization of eukaryotic cilia and flagella. Advan. Cell. Mol. Biol., 2: 193 (1972).

33. Wachstein, M., Meisel, E., and Niedzwiedz, A.: Histochemical demonstration of mitochondrial adenosine triphosphatase with the lead adenosine triphosphate technique. J. Histochem. Cytochem., 8: 387 (1960).

34. Watanabe T., and Flavin, M.: Two types of adenosine triphosphate from flagella

Copyright @ 1976 International Pediatric Research Foundation, Inc. of Chlamydomonas reinhardi. Biochem. Biophys. Res. Commun., 52: 195 (1973).

35. Wetzel, M. G., Wetzel, B. K., and Spicer, S. S.: Ultrastructural localization of acid mucosubstances in the mouse colon with iron-containing stains. J. Cell. Biol., 30: 299 (1966).

36. Wood, R. E., and di Sant'Agnese, P. A.: Bioassays of cystic fibrosis factor. Lancet, ii: 1452 (1973).

37. Eppendorf pipette, Brinkman Instruments, Inc., Westbury, N. Y

38. ICN Pharmaceuticals, Inc., Irvine, Calif.

39. Kodak N S medical x-ray film. Eastman Kodak Co., Rochester, N. Y.

40. New England Nuclear, Boston, Mass.

41. Gift of Dr. Robert S. Adelstein, National Heart and Lung Institute, National Institutes of Health, Bethesda, Md.

42. Informed consent was obtained from subjects participating in this study

43. We thank Dr. Paul A. di Sant'Agnese, Chief. Pediatric Metabolism Branch NIAMDD, for his support and guidance in all phases of this study and Anthony J. Adams, Marta M. Ulane, and Judith M. Podskalny for skilled technical help. The valuable assistance of Dr. Robert E. Wood, University Hospitals of Cleveland, Dr. James H. Conover, Mount Sinai School of Medicine, and Mr. Harold Davis, Maryland Department of Natural Resources, is also gratefully acknowledged.

44. Requests for reprints should be addressed to: P. M. Farrell, M.D., Ph.D., Neonatal and Pediatric Medicine Branch, National Institute of Child Health and Human Development, National Institutes of Health, Bldg. 10, Rm. 13N260, Bethesda, Md. 20014 (USA).

45. Accepted for publication Oct. 14, 1975.

Pediat Res. 10: 135-139 (1976)

Cardiac refractory periods electrophysiology extrastimulus technique His bundle electrogram

\title{
The Influence of Age on Cardiac Refractory Periods in Man
}

\author{
IRA W. DuBROW, ${ }^{(30)}$ EliZABETH A. FISHER, PABLO DENES, AND ALOIS R. HASTREITER \\ Sections of Pediatric and Adult Cardiology, University of Illinois Hospital and Abraham Lincoln School of \\ Medicine, Chicago, Illinois, USA
}

\section{Extract}

As age is a determinant of cardiac refractory periods, this communication describes changes of refractory periods in an age continuum of infants, children and adults, 7 months through 77 years. Seventy patients with evidence of normal $\mathrm{A}-\mathrm{V}$ conduction on scalar electrocardiogram were included. The patients were divided into six age groups: $<2$ years, 3-5 years, 6-10 years, 11-15 years, $16-30$ years, and $>30$ years. Extrastimulus technique was used to determine refractory periods in sinus rhythm or at longest cycle length assuring atrial capture, then at shorter cycle lengths. Cycle lengths $(C L)$ for each age group were divided into ranges: $C L_{1}$, 1,000-600 msec; $\mathrm{CL}_{2}, 599-460 \mathrm{msec} ; \mathrm{CL}_{3},<459 \mathrm{msec}$. Refractory periods at the three CL's within each age group were determined. Full recovery times of the A-V node within groups of children were determined. Statistical significance of the data was found by analysis of variance. The younger group tended to have shorter values than the older groups $(F<0.05-0.001)$.

\section{Speculation}

These changes with age apparently reflect maturation of the conduction system and may explain the differences in susceptibility to and electrophysiologic manifestations of various arrhythmias in infants, children, and adults.
Standard cardiac catheterization studies have contributed much to understanding hemodynamic and myocardial functions in pediatric patients. Recent advances in clinical intracardiac electrophysiology have lead to better understanding of normal and pathologic atrioventricular conduction, primarily in adults $(5,6$, $23,24,26)$. There is limited intracardiac electrophysiology data available for children $(1-4,21,22)$. DuBrow et al. (7) recently demonstrated shorter atrial and A-V nodal refractory periods in juveniles compared with adults at similar heart rates. This paper will expand our previously reported observations by examining cardiac refractory periods in multiple age groups.

\section{MATERIALS AND METHODS}

\section{PATIENT SELECTION}

Studies were performed in 70 patients, whose ages ranged from 7 months through 77 years, during diagnostic cardiac catheterization. Only patients with evidence of normal A-V conduction on scalar electrocardiogram were included (sinus rhythm, normal P-R interval, and narrow QRS). Clinical status, electrocardiographic diagnosis, and intracardiac electrogram intervals were reported previously $(5,7,26)$. Three additional children meeting the above criteria were included: two 8 year olds, one with a ventricular 